\title{
Hyperinsulinemia enhances c-Myc-mediated mammary tumor development and advances metastatic progression to the lung in a mouse model of type 2 diabetes
}

Rosalyn D Ferguson, Ruslan Novosyadlyy, Yvonne Fierz, Nyosha Alikhani, Hui Sun, Shoshana Yakar and Derek LeRoith ${ }^{*}$

\begin{abstract}
Introduction: Hyperinsulinemia, which is common in early type 2 diabetes (T2D) as a result of the chronically insulin-resistant state, has now been identified as a specific factor which can worsen breast cancer prognosis. In breast cancer, a high rate of mortality persists due to the emergence of pulmonary metastases.

Methods: Using a hyperinsulinemic mouse model $\left(\mathrm{MKR}^{+/+}\right)$and the metastatic, c-Myc-transformed mammary carcinoma cell line Mvt1, we investigated how high systemic insulin levels would affect the progression of orthotopically inoculated primary mammary tumors to lung metastases.

Results: We found that orthotopically injected Mvt1 cells gave rise to larger mammary tumors and to a significantly higher mean number of pulmonary macrometastases in hyperinsulinemic mice over a period of six weeks (hyperinsulinemic, $19.4 \pm 2.7$ vs. control, $4.0 \pm 1.3$ ). When Mvt1-mediated mammary tumors were allowed to develop and metastasize for approximately two weeks and were then surgically removed, hyperinsulinemic mice demonstrated a significantly higher number of lung metastases after a four-week period (hyperinsulinemic, $25.1 \pm$ 4.6 vs. control, $7.4 \pm 0.42$ ). Similarly, when Mvt1 cells were injected intravenously, hyperinsulinemic mice demonstrated a significantly higher metastatic burden in the lung than controls after a three-week period (hyperinsulinemic, $6.0 \pm 1.63$ vs. control, $1.5 \pm 0.68$ ). Analysis of Mvt1 cells both in vitro and in vivo revealed a significant up-regulation of the transcription factor c-Myc under hyperinsulinemic conditions, suggesting that hyperinsulinemia may promote c-Myc signaling in breast cancer. Furthermore, insulin-lowering therapy using the beta-adrenergic receptor agonist CL-316243 reduced metastatic burden in hyperinsulinemic mice to control levels.
\end{abstract}

Conclusions: Hyperinsulinemia in a mouse model promotes breast cancer metastasis to the lung. Therapies to reduce insulin levels in hyperinsulinemic patients suffering from breast cancer could lessen the likelihood of metastatic progression.

\section{Introduction}

Breast cancer incidence and progression are affected by several lifestyle factors, such as hormone therapy, body mass index, dietary intake and physical activity [1]. Type 2 diabetes (T2D) is an emerging major health concern, affecting around 285 million adults worldwide and

\footnotetext{
* Correspondence: derek.leroith@mssm.edu

Division of Endocrinology, Diabetes and Bone Diseases, The Samuel Bronfman Department of Medicine, Mount Sinai School of Medicine, New York, NY 10029, USA
}

predicted to affect up to 439 million by 2030 [2]. Epidemiological studies have recently demonstrated that the risks for breast cancer incidence and mortality are increased in individuals suffering from T2D [3-6]. A prolonged phase of pre-diabetes usually occurs before the onset of officially diagnosed T2D in which the main components of the metabolic syndrome, including dyslipidemia, hyperglycemia and hyperinsulinemia may be present for many years. For hyperinsulinemia, 
specifically, a positive correlation has recently been reported with breast cancer incidence $[7,8]$.

An array of human breast cancer specimens have been found to harbor high expression of the insulin receptor (IR) subtype A [9-11], which is involved in the mitogenic response to insulin, as opposed to IR-B which plays a major role in metabolism [12]. Likewise, in vitro, numerous studies have reported that breast cancer cell lines proliferate in response to insulin [13-15].

In the last few years our laboratory has been studying a mouse model of type 2 diabetes, which manifests hyperinsulinemia and dyslipidemia, namely the $\mathrm{MKR}^{+/+}$ mouse model. $\mathrm{MKR}^{+/+}$mice were generated a decade ago [16] by overexpression of a kinase dead insulin-like growth factor-1 receptor (IGF-IR) specifically in muscle under control of the creatine kinase promoter. Hyperinsulinemic $\mathrm{MKR}^{+/+}$female mice demonstrated enhanced mammary gland ductal branching and increased lateral bud formation. Growth and progression of orthotopicand genetically-induced mammary tumors in female MKR mice were accelerated as compared to controls, but were blocked using pharmacological inhibitors of insulin signaling or insulin-sensitizers $[17,18]$.

A high rate of mortality from breast cancer persists due to the emergence of metastases in distant organs, commonly the lungs [19]. Although studies from our laboratory and others have shown that insulin promotes primary tumor growth, studies investigating a possible connection between insulin and metastatic events in general are limited. In this study we use the hyperinsulinemic $\mathrm{MKR}^{+/+}$mouse model to study the development of mammary tumors and metastases following orthotopic injection of a highly proliferative and metastatic murine tumor cell line Mvt1, which, like many tumor types, over-expresses the transcription factor c-Myc. In $\mathrm{MKR}^{+/+}$ mice, not only do Mvt1-mediated mammary tumors develop more rapidly, but the incidence of Mvt1mediated pulmonary metastases is significantly higher. Mvt1 cells, both in vivo and in vitro, respond to hyperinsulinemia with increased expression of the transcription factor c-Myc, suggesting that high levels of insulin could increase the activity of this oncogenic factor in breast cancer. Furthermore, when we used insulin-lowering therapy in the $\mathrm{MKR}^{+/+}$mice harboring Mvt1 cells, lung metastatic burden was reduced to control levels.

\section{Materials and methods Animal studies}

Mice were housed four per cage in a clean mouse facility, fed a standard mouse chow (Purina Laboratory Chow 5001; Purina Mills (St. Louis, Missouri, USA) and water ad libitum, and kept on a 12-hour light:dark cycle. Animal care and maintenance were provided through the Mount Sinai School of Medicine AAALAC
Accredited Animal Facility. All procedures were approved by the Animal Care and Use Committee of the Mount Sinai School of Medicine according to the National Institutes of Health Guide Line. All mice were on Friend Virus B (National Institute of Health) (FVB/ N) background. For orthotopic injections, 100,000 Mvt1 cells resuspended in sterile PBS in a volume of $100 \mu \mathrm{l}$ were injected using a 30-gauge needle into the left inguinal mammary fat pad. Tumor volume was measured with calipers until tumors reached a specified dimension for resection (30 to $40 \mathrm{~mm}^{3}$ ) or until the time of sacrifice. Tumor volume was calculated using a three-coordinate system using the formula: Volume $=4 / 3 \pi$ (length $/ 2 \times$ width $/ 2 \times$ depth $/ 2$ ). For analysis of pulmonary metastases, mice were sacrificed and lungs were inflated via the trachea with $10 \%$ formalin, removed and examined for macrometastatic lesions. Lungs were embedded in paraffin, sectioned and stained using haematoxylin and eosin ( $\mathrm{H} \& \mathrm{E})$. Intravenous cell inoculations were performed by injecting 10,000 Mvt1 cells in a total volume of $100 \mu \mathrm{l}$.

\section{Cell culture}

The murine mammary cell line Mvt1 was derived from an explant culture of an MMTV c-Myc/Vegf transgenic female mouse as described elsewhere [20]. Cells were maintained in Dulbecco's Modified Eagles Medium (DMEM) supplemented with 10\% Fetal Bovine Serum (FBS) (Invitrogen, Grand Island, NY, USA), $100 \mathrm{U} / \mathrm{ml}$ penicillin and $100 \mu \mathrm{g} / \mathrm{ml}$ streptomycin (Mediatech, Manassas, VA, USA) and grown at $37^{\circ} \mathrm{C}$ in $5 \% \mathrm{CO}_{2}$ atmosphere with 95\% humidity.

\section{Western blotting}

Mvt1 cells or tumor tissues were lysed in chilled lysis buffer ( $\mathrm{pH}$ 7.4) containing $50 \mathrm{mM}$ Tris, $150 \mathrm{mM} \mathrm{NaCl}$, $1 \mathrm{mM}$ EDTA, 1.25\% CHAPS, $1 \mathrm{mM}$ sodium orthovanadate, $10 \mathrm{mM}$ sodium pyrophosphate, $8 \mathrm{mM}$ B-glycerophosphate and Complete Protease Inhibitor Cocktail tablet. Protein concentration of samples was measured using the BCA protein assay kit (Thermo Scientific, Rockford, IL, USA). Protein samples were resuspended in $3 \times$ loading buffer containing DTT (Cell Signaling Technologies, Danvers, MA, USA) and denatured by boiling for five minutes at $96^{\circ} \mathrm{C}$. Samples were then subjected to SDS polyacrylamide gel electrophoresis (SDSPAGE) and transferred to a nitrocellulose membrane. Membranes were probed with the appropriate primary antibodies: anti-phospho Akt ${ }^{\text {(Ser473) }}$, Akt, c-Myc, matrix metalloprotease (MMP) - 9 and $\beta$-actin (obtained from Cell Signaling Technology, Danvers, MA, USA), antiinsulin receptor (IR)- $\beta$, IGF-IR and vascular endothelial growth factor (VEGF) (obtained from Santa Cruz Biotechnology, Santa Cruz, CA, USA) before being 
incubated with secondary antibodies (LI-COR Biosciences, Lincoln, NE, USA) and being exposed to the LI-COR infrared detection system (LI-COR Biosciences). Semi-quantitative polymerase chain reaction (PCR)

RNA was extracted from tumor tissues using the RNeasy lipid extraction kit (QIAGEN, Valencia, CA, USA) according to the manufacturer's instructions. RNA integrity was verified using a Bioanalyzer (Agilent Technologies 2100 Bioanalyzer-Bio Sizing, Version A.02.12 SI292), (Agilent Technologies, Santa Clara, CA, USA). One $\mu \mathrm{g}$ of RNA was reverse-transcribed to cDNA using oligo (dT) primers with a RT-PCR kit according to the manufacturer's instructions (Invitrogen). After reverse transcription of RNA, cDNA was subjected to PCR cycling conditions as follows: initial denaturation at $95^{\circ}$ $\mathrm{C}$ for 2 minutes, 30 cycles of amplification consisting of a $15 \mathrm{~s}$ denaturation step at $95^{\circ} \mathrm{C}$, a $30 \mathrm{~s}$ annealing step at $58^{\circ} \mathrm{C}$, and a 1 minute extension step at $72^{\circ} \mathrm{C}$. A final seven-minute extension was performed at $72^{\circ} \mathrm{C}$. Primer sequences used were as follows: IGF-I 5' GGACCAGAGACCCTTTGCGGGG, IGF-I 3' GGCTGCTTTTGT AGGCT TCAGTGG, IGF-II 5' CCTTCGCCTTGTGCT GCAT, IGF-II 3' ACGGTTGGCACGGCTTAA, $\beta$-actin 5' CCTAAGGCCAACCGTGAAAA, $\beta$-actin 3' GAGGC ATACAGGGACAGCACA.

\section{Proliferation assays}

Mvt1 cells were seeded in 24-well plates at a density of $1 \times 10^{4}$ cells $/ \mathrm{ml}$ and allowed to adhere for 24 hours. Standard growth medium was then exchanged for serum-free DMEM containing 0.1\% BSA and cells were allowed to rest for one hour before the addition of insulin. Cells were incubated with insulin at concentrations of $10 \mathrm{nM}$ or $100 \mathrm{nM}$ for 72 hours and medium was changed daily. Cells were then trypsinized, diluted in trypan blue (1:2) and counted by haemocytometer using trypan blue exclusion.

\section{Statistical analysis}

Results are expressed as means \pm SEM. Statistical analyses were conducted using the Student's $t$-test and, where appropriate, two-way ANOVA followed by Tukey HSD post-hoc test, with $P \leq 0.05$ considered significant.

\section{Results \\ In $\mathrm{MKR}^{+/+}$mice, orthotopically injected Mvt1 cells form larger primary tumors and exhibit more pulmonary metastases than in control mice}

The metabolic characteristics of female $\mathrm{MKR}^{+/+}$mice have been described and illustrated previously $[17,18]$. The principal abnormalities in these mice include severe insulin resistance and hyperinsulinemia on a background of mild dysglycemia (approximately $20 \%$ elevated blood glucose compared to controls). Female $\mathrm{MKR}^{+/+}$mice are non- obese and weigh moderately less than control mice. In addition, total body fat in $\mathrm{MKR}^{+/+}$is lower than in controls and inflammatory factors commonly elevated in obesity are expressed at normal levels. We injected 100,000 Mvt1 cells into the left inguinal mammary pad of 8- to10 -week-old control and $\mathrm{MKR}^{+/+}$mice and monitored growth of mammary tumors weekly. A significant increase in Mvt1-mediated mammary tumor growth was observed in $\mathrm{MKR}^{+/+}$mice compared to controls (Figure 1A), which was confirmed by the terminal weights of tumors (Figure 1B). At the time of sacrifice (six weeks after cell injection), lungs from control and $\mathrm{MKR}^{+/+}$mice were removed and macrometastases were counted. The mean number of macrometastases/mouse was significantly higher in MKR ${ }^{+/+}$mice (mean number of macrometastases $=19.4 \pm 2.7$ ) compared to controls (mean number of metastases $=4.0 \pm$ 1.3) (Figure 1C). Lungs of representative groups of MKR ${ }^{+/+}$mice $(\mathrm{n}=3)$ and control mice $(\mathrm{n}=3)$ were paraffinembedded, sectioned and stained with $\mathrm{H}$ \& $\mathrm{E}$ to verify the increased incidence of metastatic lesions in $\mathrm{MKR}^{+/+} \mathrm{com}-$ pared to control mice (Figure 1D).

The incidence of pulmonary metastases remains higher in $\mathrm{MKR}^{+/+}$mice compared to controls, independent of mammary tumor size

It is possible that the significantly increased number of macrometastases in $\mathrm{MKR}^{+/+}$mice is simply a consequence of larger tumors at the primary site, which could promote greater tumor cell dissemination. To eliminate the effect of primary tumor size on metastasis occurrence, we controlled for primary tumor size. Separate cohorts of 8- to 10 -week-old control and $\mathrm{MKR}^{+/+}$mice were injected in the inguinal mammary fat pad with 100,000 Mvt1 cells. Mammary tumor volume was measured with calipers twice-weekly. When tumors reached a volume of 30 to $40 \mathrm{~mm}^{3}$ (14 to 16 days following cell injection, (data not shown) they were surgically removed. Tumor volumes (Figure $2 \mathrm{~A}$ ) and weights (Figure $2 \mathrm{~B}$ ) at the time of resection demonstrated no significant difference between $\mathrm{MKR}^{+/+}$and control mice.

After tumor resection, mice were returned to their original housing for a period of four weeks and were then sacrificed. Lungs from all mice were removed and pulmonary macrometastases quantified. A significant increase in the number of metastases was observed in $\mathrm{MKR}^{+/+}$mice (mean number of metastases $=25.1 \pm 4.6$ ) compared to controls (mean number of metastases $=7.4$ \pm 0.42 ) (Figure 2C).

When equal numbers of Mvt1 cells are injected intravenously into control and $\mathrm{MKR}^{+/+}$mice, lung metastatic burden is higher in $\mathrm{MKR}^{+/+}$mice In $\mathrm{MKR}^{+/+}$mice, insulin levels are increased and may promote mitogenesis through activation of the IR. To 


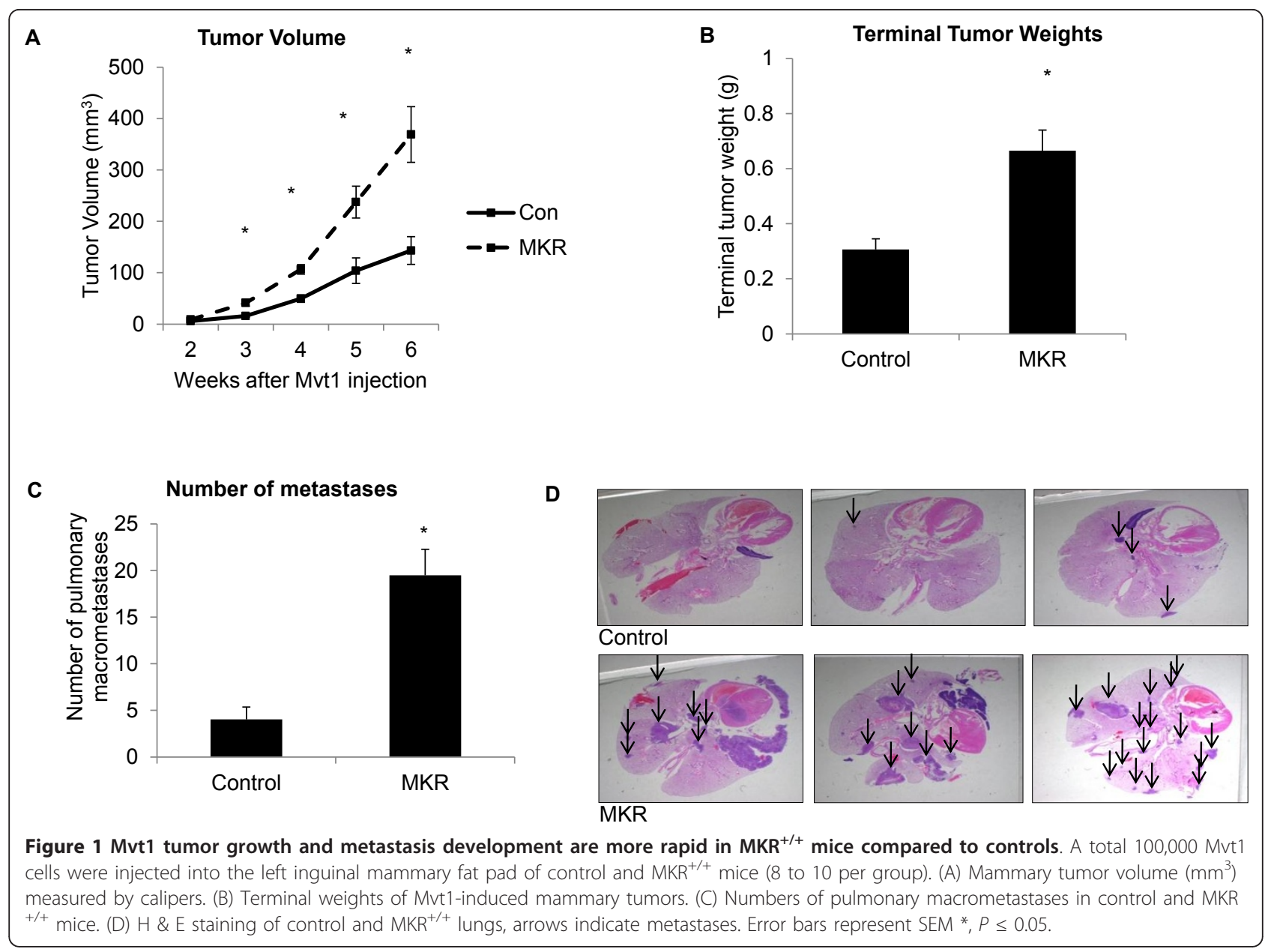

address whether metastatic lesions in the lungs of MKR ${ }^{+/+}$mice exhibit greater proliferative activity than those in the lungs of control mice, an equal amount of Mvt1 cells $(10,000)$ were injected intravenously into both $\mathrm{MKR}^{+/+}$and control mice. After three weeks, all mice were sacrificed and examined for pulmonary metastases. Significantly more metastases were observed in lungs of $\mathrm{MKR}^{+/+}$mice compared to controls $\left(\mathrm{MKR}^{+/+}, 6 \pm 1.63\right.$ vs. control, $1.5 \pm 0.68$ ) (Figure $2 \mathrm{D}$ ) indicating that the environment of the hyperinsulinemic lung is more permissive for the proliferation of circulating tumor cells.

Mammary tumors express elevated levels of c-Myc, MMP9, IR, IGF-IR and VEGF

In order to examine the effects of hyperinsulinemia on the metastasis of tumor cells from the primary site, we examined levels of c-Myc, MMP-9, IR, IGF-IR and VEGF in tumor tissue extracted from control and MKR ${ }^{+/+}$mice. As shown in Figure $3 \mathrm{~A}, \mathrm{~B}$, in $\mathrm{MKR}^{+/+}$mice, expression levels of c-Myc, IR, IGF-IR and VEGF were significantly up-regulated compared to controls. MMP-9 expression was also elevated, although overall, a statistically significant increase was not observed. As hyperinsulinemia can also affect the expression level of IGFI and IGFII, we used semi-quantitative PCR to compare the levels of both $I g f 1$ and Igf2 mRNA in $\mathrm{MKR}^{+/+}$ and control mice. As shown in Figure 3C, D, we did not detect any difference in expression of Igfl in tumors from $\mathrm{MKR}^{+/+}$and control mice. We found Igf 2 levels to be barely detectable in tumors and could thus not observe any significant difference in levels of Igf2 mRNA in $\mathrm{MKR}^{+/+}$versus control mice.

Insulin stimulates Akt phosphorylation and increased proliferation in mammary tumor cell line Mvt1 in vitro, and increases the expression of c-Myc and MMP-9

In order to find a potential mechanism to explain why Mvt1 cells grow faster and metastasize more readily in the presence of elevated insulin, we studied their reaction to insulin stimulation in vitro. Initially we verified that Mvt1 cells demonstrated a typical response to insulin stimulation. Short-term stimulation of Mvt1 cells with up to $20 \mathrm{nM}$ insulin caused robust phosphorylation of Akt (Figure 4A), a central signaling protein and key 


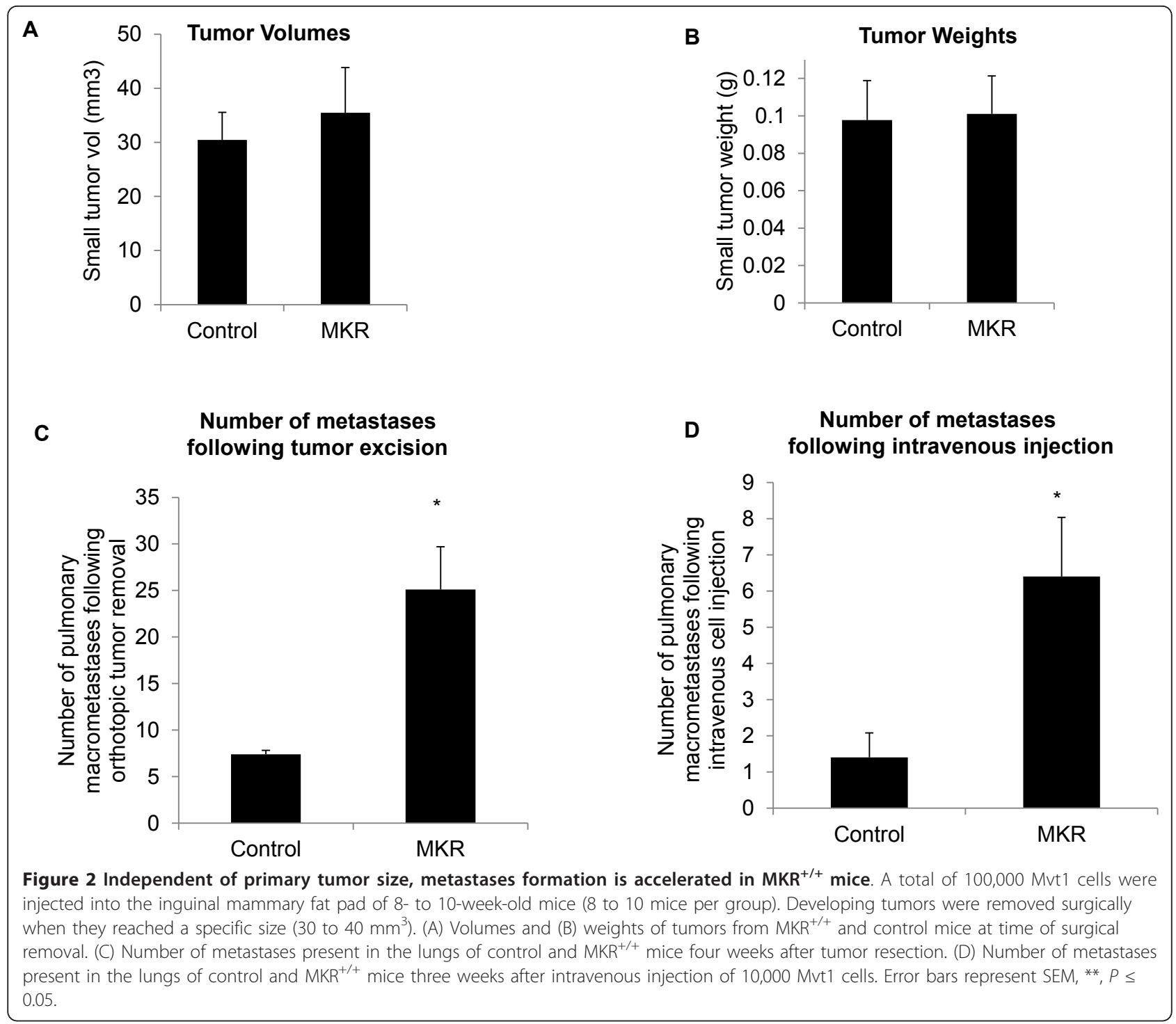

mediator of insulin action downstream of the IR, demonstrating that Mvt1 cells respond appropriately to insulin. We observed no change in the phosphorylation of Erk1 and Erk2 in response to insulin stimulation. To determine whether insulin also affects the proliferation of Mvt1 cells in vitro, cells were seeded at a density of 1 $\times 10^{4}$ cells $/ \mathrm{ml}$ in 24-well plates and stimulated with 10 $\mathrm{nM}$ or $100 \mathrm{nM}$ insulin for 72 hours. Viable cell number was assessed by trypan blue exclusion using a haemocytometer. The presence of insulin at both $10 \mathrm{nM}$ and 100 $\mathrm{nM}$ was sufficient to cause a significant increase in the proliferation of Mvt1 cells in vitro (Figure 4B).

Mvt1 cells, like many other tumor types, over-express c-Myc, a transcription factor which is regulated by several extracellular growth factors [21]. We investigated whether insulin could alter the expression of c-Myc in Mvt1 cells in vitro. Cells were serum-starved for $72 \mathrm{~h}$ and then stimulated with $10 \mathrm{nM}$ and $100 \mathrm{nM}$ insulin for up to one hour. As shown in Figure 4C, exposure of Mvt1 cells to insulin caused an increase in the expression levels of c-Myc. Mvt1 cells are a highly metastatic cell line; we thus also investigated whether MMP-9, a key protein involved in cell metastasis from primary tumors, was affected by insulin stimulation in vitro. As shown in Figure 4C, insulin stimulation increased MMP-9 levels, demonstrating that insulin may also enhance cell signaling pathways which lead to metastasis from the site of primary tumors in breast cancer.

\section{Insulin-reducing therapy decreases the incidence of} pulmonary metastases in $\mathrm{MKR}^{+/+}$mice

To examine whether the increased metastatic burden in $\mathrm{MKR}^{+/+}$mice was insulin-mediated, we used a pharmacological agent to lower insulin levels and then observed 


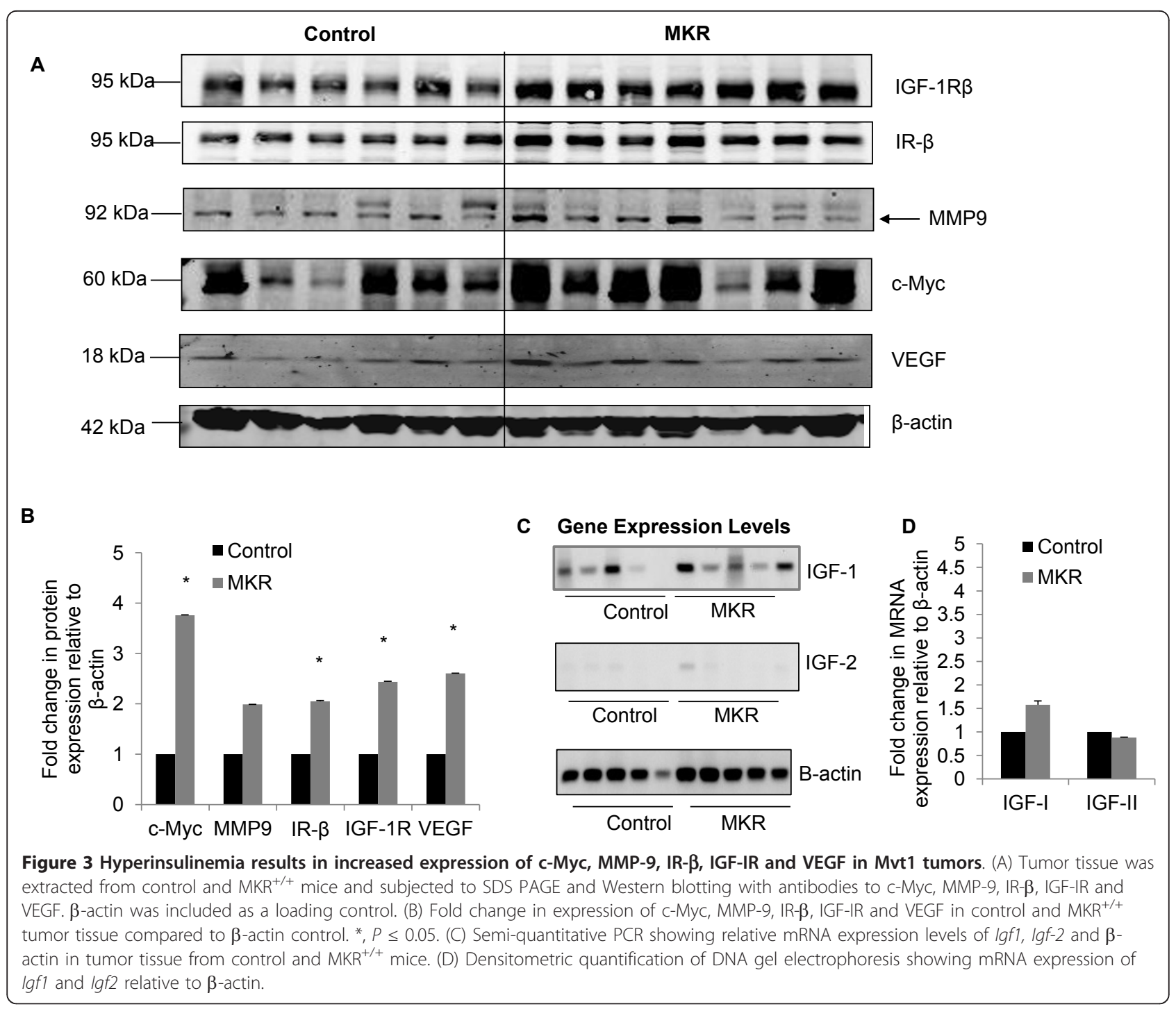

the result of this intervention on metastases formation in the lung. CL-316243 is a potent and highly selective $\beta_{3}$-adrenoceptor agonist, which decreases blood insulin and glucose levels following oral administration in vivo [22]. In our previous studies we have shown that CL316243 dramatically improved the diabetic state in male $\mathrm{MKR}^{+/+}$mice by reducing circulating glucose and insulin levels and enhancing whole body metabolic rate [23]. Furthermore, we have shown that CL-316243 treatment in female $\mathrm{MKR}^{+/+}$mice, caused a significant decrease in the growth rate of both PyVmT and Neu/ErbB2 cellmediated mammary tumors [17]. To assess the effect of CL-316243 treatment on the metastatic growth of Mvt1 cells, both $\mathrm{MKR}^{+/+}$and control mice were injected intravenously with 10,000 Mvt1 cells. Mice were then treated with either CL-316243 ( $1 \mathrm{mg} \cdot \mathrm{kg}$ body $\left.\mathrm{wt}^{-1} \mathrm{day}^{-1}\right)$ or vehicle for three weeks. During the CL-316243 or vehicle treatment period, we monitored metabolic parameters. As shown in Figure $5 \mathrm{~A}, \mathrm{MKR}^{+/+}$mice demonstrated a significant reduction of total fat mass as well as a reduction in serum insulin levels (Figure 5A, D) and a concomitant decrease in blood sugar (Figure 5B). In control mice, no change in insulin levels was observed (Figure 5D). Throughout the CL-316243 treatment, no change in body weight was observed in control or $\mathrm{MKR}^{+/+}$mice (Figure $5 \mathrm{C}$ ), consistent with our previous observations [17].

At the end of the treatment period, all mice were sacrificed and numbers of macrometastases were quantified. As shown in Figure 5E, we observed a significant reduction in the numbers of Mvt1-mediated metastases in $\mathrm{MKR}^{+/+}$mice treated with CL-316243 and no effect in controls, suggesting that reductions in insulin levels, independent of primary mammary tumor size, could directly lower the incidence of Mvt1 metastases in MKR ${ }^{+/+}$mice. 


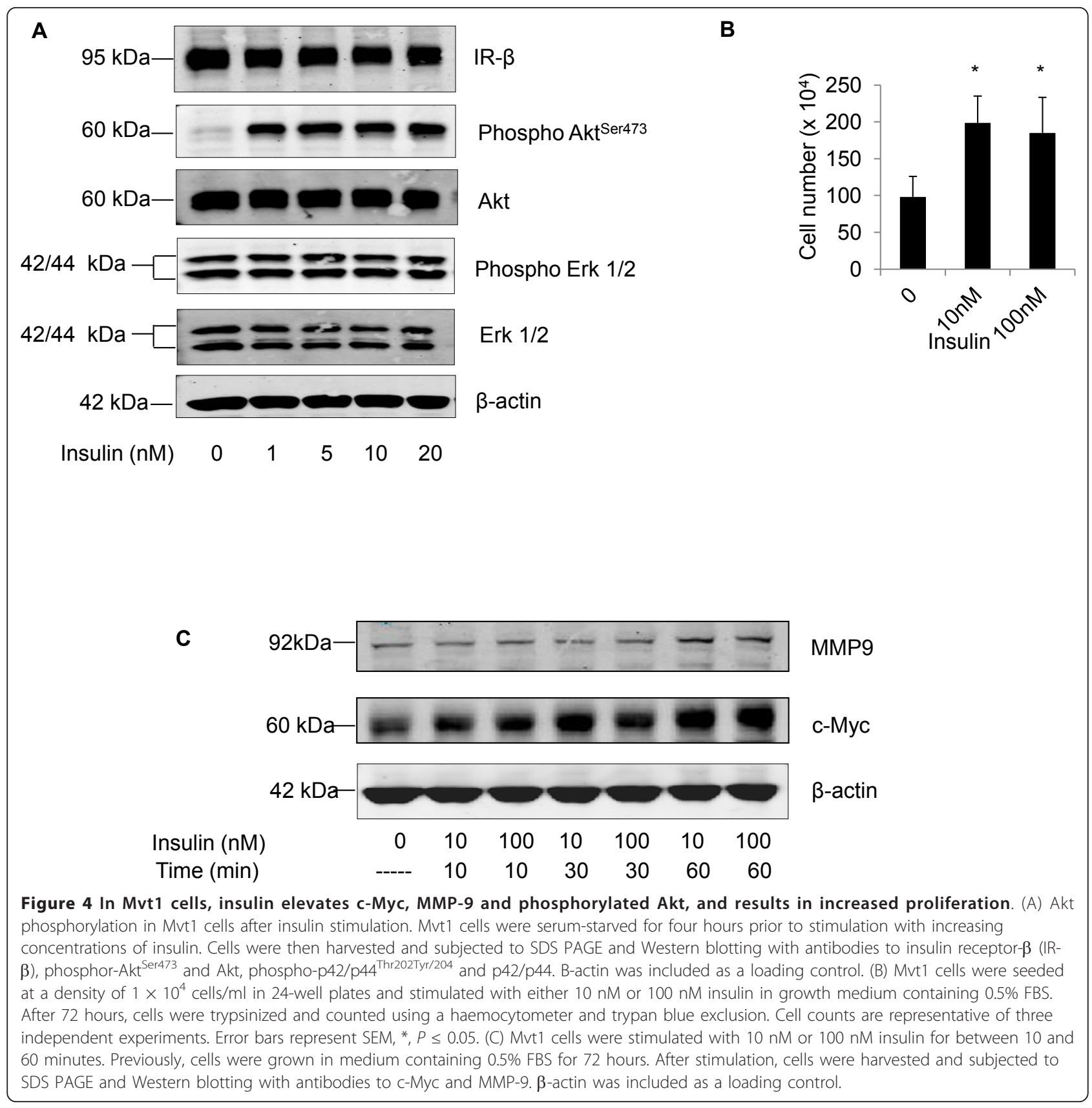

\section{Discussion}

Several epidemiological studies have demonstrated that the risks of breast cancer incidence and mortality are both positively associated with type 2 diabetes (T2D), a multi-factorial disease encompassing several metabolic dysfunctions, such as insulin resistance and hyperinsulinemia, hyperglycemia and dyslipidemia [3-6,24]. Additionally, hyperinsulinemia, specifically, is a significant risk factor for breast cancer incidence, independent of other factors associated with type 2 diabetes [7]. Breast cancer mortality rates remain high, primarily due to the metastasis of primary tumors to distant organs, such as the lungs [25]. In type 2 diabetic patients, it is possible that breast cancer metastasis may also be augmented by metabolic dysfunctions; thus we investigated in a mouse model whether hyperinsulinemia, specifically, affects the metastasis of primary mammary tumors to the lung.

We used the female $\mathrm{MKR}^{+/+}$mouse, which manifests severe insulin resistance and hyperinsulinemia, yet is only mildly hyperglycemic and leaner than controls. Previous work from our laboratory has established that two different murine mammary tumor cell lines (Met1 and 


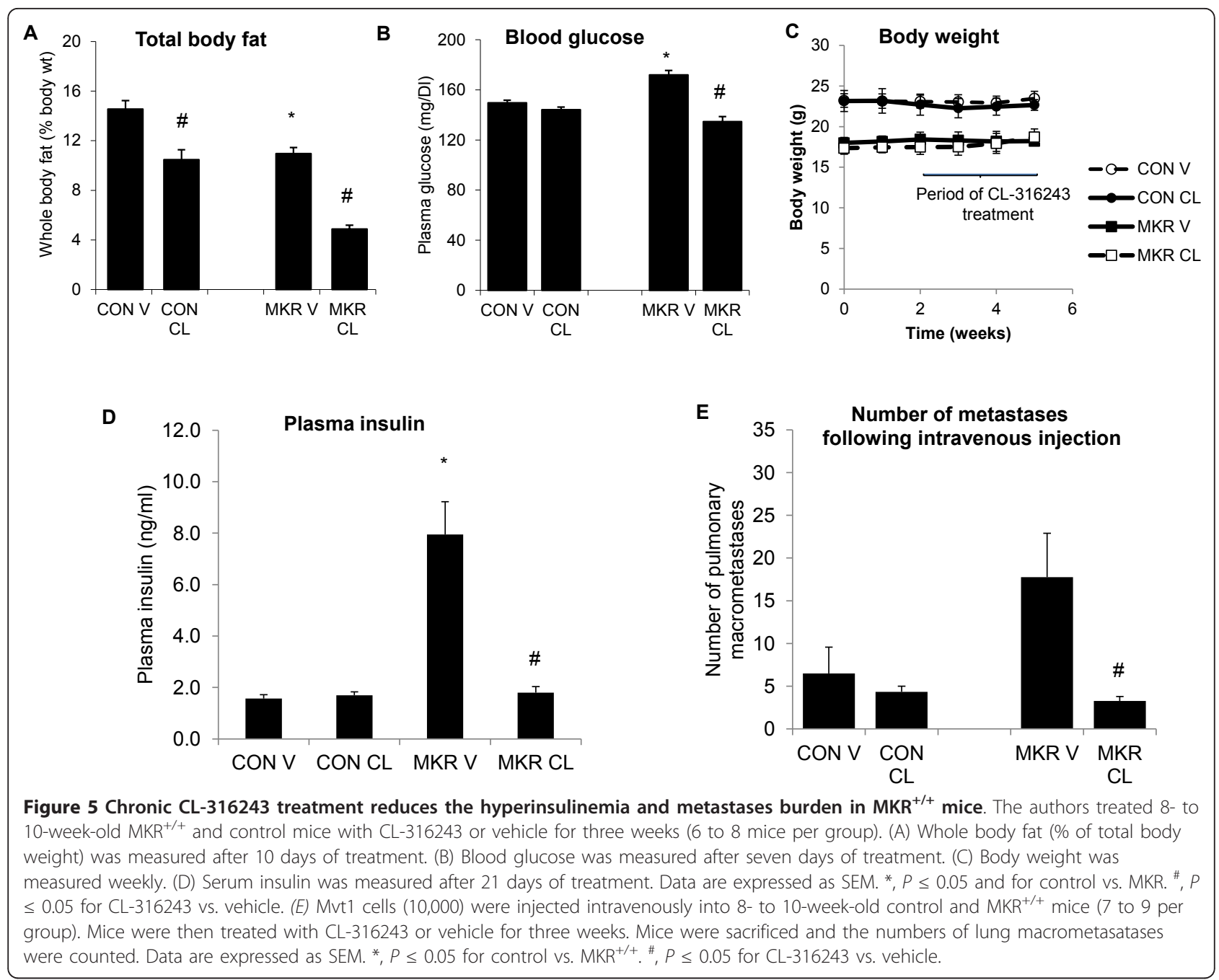

MCNeuA) develop significantly larger orthotopic tumors in $\mathrm{MKR}^{+/+}$mice compared to controls, demonstrating a potent effect of hyperinsulinemia on mammary tumor development $[17,18]$. We now use an alternative mouse mammary tumor cell line, Mvt1, which spontaneously metastasizes from orthotopically-induced mammary tumors in order to study the effect of hyperinsulinemia, during type 2 diabetes, on the progression of primary tumors to metastases. When inoculated, Mvt1 cells form significantly larger tumors in $\mathrm{MKR}^{+/+}$mice than in controls, a finding which reinforces our previous data on hyperinsulinemia and mammary tumor development. Furthermore, the number of spontaneous metastases in the lungs of $\mathrm{MKR}^{+/+}$mice is also greater than in controls, demonstrating a positive association between hyperinsulinemia and mammary tumor metastasis.

A relationship between hyperinsulinemia and breast cancer progression to metastasis has not been verified by clinical studies. However, experimental data indicate that the major events of primary tumor metastasis, such as migration, invasion and angiogenesis, are enhanced by elevated insulin levels. Chinese Hamster Ovary (CHO) cells overexpressing the IR become highly chemotactic toward insulin stimulation [26]. Insulin increases the migration and invasion of human hepatocarcinoma cell line H7721, and its adhesion to human umbilical vein endothelial cells (HUVEC). Furthermore, these metastases-related effects can be reversed by the addition of an inhibitor to phosphatidylinositide 3kinase (PI3-K), one of the main signaling molecules downstream of activated IR [27]. In an in vivo study of orthotopically-induced mouse mammary tumors progressing to lung metastases, down-regulation of the IR in tumor cells results in reduced primary tumor growth and fewer pulmonary lesions, along with diminished angiogenesis, demonstrating an important role for insulin signaling in cancer progression [28].

We observed more spontaneous metastases in the lungs of $\mathrm{MKR}^{+/+}$mice compared to controls; however, we identified that this finding could be due simply to 
the larger tumors in $\mathrm{MKR}^{+/+}$mice, rather than a response to insulin. Our surgical removal of tumors from $\mathrm{MKR}^{+/+}$and control mice when they reached a specific size $\left(35\right.$ to $40 \mathrm{~mm}^{3}$ ) demonstrated that more metastasis had already occurred in $\mathrm{MKR}^{+/+}$mice compared to controls, apparent from the greater number of metastases which were later detected in the lungs. This demonstrates the potent effect of elevated insulin in advancing the metastatic spread of tumor cells.

Our analysis of tumor tissue reveals increased c-Myc expression in tumors of $\mathrm{MKR}^{+/+}$mice compared to controls. c-Myc is a transcription factor which controls cellcycle progression, metabolism and differentiation, and is expressed at low levels in normal resting cells [29]. Activation of c-Myc depends on its formation of a heterodimeric complex with Max [30]. Around 50\% of breast cancers are a consequence of c-Myc-driven oncogenic transformation, which occurs by gene amplification, chromosomal translocation or protein overexpression and stabilization [29,31-33]. Certain growth factors augment oncogenic c-Myc expression in human breast cancer, including TGF $\alpha$ and IGF-I [34-36]. Insulin can upregulate $\mathrm{c}-\mathrm{Myc}$ in the estrogen-driven human breast cancer cell line MCF-7, which is augmented by the addition of estradiol [37]. Additionally, both insulin and IGF-I have been reported to stimulate expression of cMyc in non-transformed bovine fibroblast cells in culture [38]. To our knowledge, there are no reports of insulin influencing c-Myc levels in an in vivo setting; thus, we believe that ours are the first data to demonstrate this association. In our model, we observed elevated c-Myc expression in the presence of high insulin levels both in vivo and in vitro. We also observed increased tumor mass and cell proliferation, respectively, suggesting a role for insulin in significantly promoting the growth-mediating effects of c-Myc.

c-Myc is integrally involved in breast cancer metastasis, promoting loss of apoptosis, invasion, and angiogenesis [39-42]. Thus, in addition to accelerating cell proliferation, insulin-mediated increases in c-Myc expression could potentially enhance metastatic events. Indeed, in our model, increased c-Myc was associated with elevated levels of MMP-9 and VEGF, which are both important mediators of metastatic events in vivo $[43,44]$. MMP-9 is a key protease secreted from metastatic cells, which implements proteolytic modification or degradation of the extracellular matrix during tumor cell dissemination [45]. Knock-down of c-Myc in a murine lung cancer model led to a reduction in MMP-9 levels and diminished metastasis of lung tumor cells to distant sites [46]. It has also been reported that MMP-9 is a direct target of c-Myc in cultured murine lymphoid endothelial cells during the initiation and progression of atherosclerotic lesions [47].
VEGF is a key mediator of angiogenesis and is essential for intravasation of metastasizing tumor cells [43] as well as for primary tumor development [48]. Transgenic mice overexpressing $\mathrm{c}-\mathrm{Myc}$ in the mammary gland resulted in low rates of lung micrometastases, whereas when c-Myc and VEGF were expressed simultaneously, high rates of macrometastases occurred [49]. In the ascites of patients with metastatic ovarian cancer, lysophosphatidic acid (LPA) stimulated expression of VEGF, an event which was completely dependent on c-Myc expression [50]. In agreement with these data, we observed increased VEGF in tumor tissue which also expressed elevated levels of c-Myc.

We also demonstrated a significant up-regulation of the IR and an elevation of the IGF-IR in tumors from $\mathrm{MKR}^{+/+}$mice. Although human clinical studies have not investigated levels of the IR in breast tumors from hyperinsulinemic patients, specifically, it has been reported that IR expression, as well as being a strong predictor of poor survival rate, spans all three subsets of clinical breast cancer (luminal, Her2 positive and triple negative) $[9,10]$, and mammary tumorigenesis in mice resulting from transgenic expression of $\mathrm{Neu}$, Wnt1, or Ret oncogenes is accompanied by significant elevations of IR levels in all three tumor types [51]. These data all suggest that increased IR expression is linked to the onset or development of breast cancer. The IGF-IR is highly homologous to the IR, activates similar signaling pathways when bound by IGFI/II, and has a well-established role in the progression of breast cancer [52]. It has been reported that insulin itself can increase IGF-IR levels [53]. Hyperinsulinemia is also known to increase circulating IGF1 production, either by up-regulating growth hormone receptor levels [54] or by suppressing IGF binding protein (IGFBP) -1 and -2 [55]. However, we found no significant difference in Igf1 mRNA levels in the tumor tissue of $\mathrm{MKR}^{+/+}$and control mice, suggesting that any differences in tumor growth or metastases formation were due to insulin rather than IGF-I. It is known that IGF-II causes activation of the IR [12]; but its expression is confined mainly to fetal development and thus circulates at extremely low levels postnatally in rodents [56]. Indeed, in tumor tissue from both control and $\mathrm{MKR}^{+/+}$mice we observed barely detectable levels of Igf2 mRNA expression.

Our finding of increased metastatic burden following intravenous injection of Mvt1 cells in the absence of a primary tumor suggests that hyperinsulinemia promotes increased survival or proliferation (or both) of circulating tumor cells that arrest in the lungs. Our in vitro data confirm that insulin stimulates the expected canonical Akt signaling pathway in Mvt1 cells and also enhances Mvt1 proliferation. The significantly reduced number of lung metastases, which we observed after 
three weeks of insulin-lowering treatment with CL316243 , suggests that reducing insulin levels causes a decrease in either survival or proliferation of Mvt1 cells in the lungs. In agreement with this finding, previous work from our laboratory has reported an abrogation of both PyVmT- and Neu- mediated orthotopic mammary tumor growth during chronic CL-316243 treatment [17].

In summary, we have used a hyperinsulinemic mouse model to study the effect of elevated systemic insulin levels on mammary tumor metastasis to lung. As well as confirming previously published data whereby insulin accelerates primary tumor growth, we also provide important new findings which suggest that insulin also affects breast cancer progression to the metastatic stage. This indicates that breast cancer patients presenting with hyperinsulinemia may be at increased risk of primary tumor progression to lung metastases. These data could explain, in part, the increased mortality in patients with breast cancer and T2D and highlights the benefit of using insulin-reducing therapies to reduce the mortality risk from the combined effect of these two diseases.

\section{Conclusions}

Hyperinsulinemia in vivo can significantly increase both primary tumor growth and subsequent metastasis to the lung in a mouse model. During periods of hyperinsulinemia, the lungs may provide an environment which can augment the survival or proliferation of metastatic cells. Oncogenic c-Myc expression is increased during periods of hyperinsulinemia, both in vivo and in vitro and this could contribute both to primary tumor growth and metastatic events. Finally, insulin-reducing treatment can significantly diminish the growth of intravenously inoculated metastatic cells in the lungs, suggesting that therapies to lower insulin in breast cancer patients presenting with hyperinsulinemia could be a valuable strategy to reduce mortality from breast cancer metastatic progression.

\footnotetext{
Abbreviations

CHAPS: 3-((3-cholamidopropyl)dimethylammonio)-1-propanesulfonate; CHO: Chinese Hamster Ovary; DTT: dithiothreitol; EDTA: ethylene diamine tetraacetic acid; HUVEC: human umbilical vein endothelial cells; IGF-IR: insulin-like growth factor 1 receptor; IR: insulin receptor; LPA: Iysophosphatidic acid; MKR: (MCK) muscle creatinine kinase: KR (arg to lys substitution to create a dominānt negative IGF-IR); MMP: matrix metalloprotease; PI3-K: phosphatidylinositide 3-kinase; PyVmT: polyoma virus middle T antigen; T2D: type 2 diabetes; VEGF: vascular endothelial growth factor
}

\section{Acknowledgements}

We thank K. Hunter (Center for Cancer Research, National Cancer Institute, US national Institute of Health) for donating Mvt1 cells and Dr Yingjie Wu for semi-quantitative PCR primers. The grant for this work was support to DL (RO1CA128798-01A3 (NIH). Y. Fierz was funded by Swiss National Science Foundation grant PBBSB-120851, the Novartis Foundation, the Roche Research Foundation and the Oncosuisse Foundation.

\section{Authors' contributions}

RF performed in vivo and in vitro experiments, experimental design and strategies, and manuscript preparation. RN obtained Mvt1 cells, contributed to experimental design and strategies, provided preliminary data on metastatic potential of Mvt1 cells, and contributed to/edited the manuscript. YF contributed to experimental strategies, provided training on animal injections/surgery, and contributed to/edited the manuscript. NA provided assistance with in vivo procedures/animal surgery, performed RNA extraction and PCR reactions, and contributed to editing of the manuscript. HS provided training in animal surgery/techniques. SY contributed to experimental strategies, training on animal surgery/techniques, and contributed to/edited the manuscript. DL is the Principal Investigator and corresponding author on the project, obtained funding, and contributed to experimental strategies and editing of/contributions to the manuscript. All authors read and approved the final manuscript.

\section{Competing interests}

The authors declare that they have no competing interests.

Received: 13 July 2011 Revised: 31 October 2011

Accepted: 7 January 2012 Published: 7 January 2012

\section{References}

1. Gerber B, Muller H, Reimer T, Krause A, Friese K: Nutrition and lifestyle factors on the risk of developing breast cancer. Breast Cancer Res Treat 2003, 79:265-276.

2. Shaw JE, Sicree RA, Zimmet PZ: Global estimates of the prevalence of diabetes for 2010 and 2030. Diabetes Res Clin Pract 2010, 87:4-14.

3. Barone BB, Yeh HC, Snyder CF, Peairs KS, Stein KB, Derr RL, Wolff AC, Brancati FL: Long-term all-cause mortality in cancer patients with preexisting diabetes mellitus: a systematic review and meta-analysis. JAMA 2008, 300:2754-2764.

4. Coughlin SS, Calle EE, Teras LR, Petrelli J, Thun MJ: Diabetes mellitus as a predictor of cancer mortality in a large cohort of US adults. Am J Epidemiol 2004, 159:1160-1167.

5. Larsson SC, Mantzoros CS, Wolk A: Diabetes mellitus and risk of breast cancer: a meta-analysis. Int J Cancer 2007, 121:856-862.

6. Xue F, Michels KB: Diabetes metabolic syndrome, and breast cancer: a review of the current evidence. Am J Clin Nutr 2007, 86:5823-835.

7. Gunter MJ, Hoover DR, Yu H, Wassertheil-Smoller S, Rohan TE, Manson JE, Li J, Ho GY, Xue X, Anderson GL, Kaplan RC, Harris TG, Howard BV, WylieRosett J, Burk RD, Strickler HD: Insulin, insulin-like growth factor-l, and risk of breast cancer in postmenopausal women. J Natl Cancer Inst 2009, 101:48-60.

8. Lipscombe LL, Goodwin PJ, Zinman B, McLaughlin JR, Hux JE: Increased prevalence of prior breast cancer in women with newly diagnosed diabetes. Breast Cancer Res Treat 2006, 98:303-309.

9. Law JH, Habibi G, Hu K, Masoudi H, Wang MY, Stratford AL, Park E, Gee JM, Finlay P, Jones HE, Nicholson Rl, Carboni J, Gottardis M, Pollak M, Dunn SE: Phosphorylated insulin-like growth factor-i/insulin receptor is present in all breast cancer subtypes and is related to poor survival. Cancer Res 2008, 68:10238-10246.

10. Mathieu MC, Clark GM, Allred DC, Goldfine ID, Vigneri R: Insulin receptor expression and clinical outcome in node-negative breast cancer. Proc Assoc Am Physicians 1997, 109:565-571.

11. Papa V, Pezzino V, Costantino A, Belfiore A, Giuffrida D, Frittitta L, Vannelli GB, Brand R, Goldfine ID, Vigneri R: Elevated insulin receptor content in human breast cancer. J Clin Invest 1990, 86:1503-1510.

12. Frasca F, Pandini G, Scalia P, Sciacca L, Mineo R, Costantino A, Goldfine ID, Belfiore A, Vigneri R: Insulin receptor isoform A, a newly recognized, high-affinity insulin-like growth factor II receptor in fetal and cancer cells. Mol Cell Biol 1999, 19:3278-3288.

13. Osborne CK, Bolan G, Monaco ME, Lippman ME: Hormone responsive human breast cancer in long-term tissue culture: effect of insulin. Proc Natl Acad Sci USA 1976, 73:4536-4540.

14. Bentel JM, Lebwohl DE, Cullen K, Rubin MS, Rosen N, Mendelsohn J, Miller WH Jr: Insulin-like growth factors modulate the growth inhibitory effects of retinoic acid on MCF-7 breast cancer cells. J Cell Physiol 1995, 165:212-221.

15. Gliozzo B, Sung CK, Scalia P, Papa V, Frasca F, Sciacca L, Giorgino F, Milazzo G, Goldfine ID, Vigneri R, Pezzino V: Insulin-stimulated cell growth 
in insulin receptor substrate-1-deficient ZR-75-1 cells is mediated by a phosphatidylinositol-3-kinase-independent pathway. J Cell Biochem 1998, 70:268-280.

16. Fernandez AM, Kim JK, Yakar S, Dupont J, Hernandez-Sanchez C, Castle AL, Filmore J, Shulman Gl, Pezzino V: Insulin-stimulated cell growth in insulin receptor substrate-1-deficient ZR-75-1 cells is mediated by a phosphatidylinositol-3-kinase-independent pathway. Genes Dev 2001, 15:1926-1934.

17. Fierz Y, Novosyadlyy R, Vijayakumar A, Yakar S, LeRoith D: Insulinsensitizing therapy attenuates type 2 diabetes-mediated mammary tumor progression. Diabetes 2010, 59:686-693.

18. Novosyadlyy R, Lann DE, Vijayakumar A, Rowzee A, Lazzarino DA, Fierz Y Carboni JM, Gottardis MM, Pennisi PA, Molinolo AA, Kurshan N, Mejia W, Santopietro S, Yakar S, Wood TL, LeRoith D: Insulin-mediated acceleration of breast cancer development and progression in a nonobese model of type 2 diabetes. Cancer Res 2010, 70:741-751.

19. Minn AJ, Gupta GP, Siegel PM, Bos PD, Shu W, Giri DD, Viale A, Olshen AB, Gerald WL, Massague J: Genes that mediate breast cancer metastasis to lung. Nature 2005, 436:518-524.

20. Pei XF, Noble MS, Davoli MA, Rosfjord E, Tilli MT, Furth PA, Russell R, Johnson MD, Dickson RB: Explant-cell culture of primary mammary tumors from MMTV-c-Myc transgenic mice. Vitro Cell Dev Biol Anim 2004 40:14-21.

21. Takai Y, Kaibuchi K, Tsuda T, Yamashita T, Kikuchi A, Tanimoto T, Hoshijima M, Hoshijima M: [Possible modes of action of growth factors and tumor promoters in the activation of the c-myc gene in Swiss 3T3 fibroblasts]. Gan To Kagaku Ryoho 1986, 13:798-805.

22. Bloom JD, Dutia MD, Johnson BD, Wissner A, Burns MG, Largis EE, Dolan JA, Claus TH: Disodium (R, R)-5-[2-[[2-(3-chlorophenyl)-2-hydroxyethyl]amino] propyl]-1,3-benzodioxole-2,2-dicarboxylate (CL 316,243). A potent beta-adrenergic agonist virtually specific for beta 3 receptors. A promising antidiabetic and antiobesity agent. J Med Chem 1992, 35:3081-3084

23. Kim H, Pennisi PA, Gavrilova O, Pack S, Jou W, Setser-Portas J, East-Palmer J, Tang Y, Manganiello VC, Leroith D: Effect of adipocyte beta3-adrenergic receptor activation on the type 2 diabetic MKR mice. Am J Physiol Endocrinol Metab 2006, 290:E1227-1236.

24. Peairs KS, Barone BB, Snyder CF, Yeh HC, Stein KB, Derr RL, Brancati FL, Wolff AC: Diabetes mellitus and breast cancer outcomes: a systematic review and meta-analysis. J Clin Oncol 2011, 29:40-46.

25. Solomayer EF, Diel IJ, Meyberg GC, Gollan C, Bastert G: Metastatic breast cancer: clinical course, prognosis and therapy related to the first site of metastasis. Breast Cancer Res Treat 2000, 59:271-278.

26. Yenush L, Kundra V, White MF, Zetter BR: Functional domains of the insulin receptor responsible for chemotactic signaling. J Biol Chem 1994, 269:100-104

27. Qi HL, Zhang Y, Ma J, Guo P, Zhang XY, Chen HL: Insulin/protein kinase B signalling pathway upregulates metastasis-related phenotypes and molecules in H7721 human hepatocarcinoma cell line. Eur J Biochem 2003, 270:3795-3805.

28. Zhang H, Fagan DH, Zeng X, Freeman KT, Sachdev D, Yee D: Inhibition of cancer cell proliferation and metastasis by insulin receptor downregulation. Oncogene 2010, 29:2517-2527.

29. XU J, Chen Y, Olopade OI: MYC and Breast Cancer. Genes Cancer 2010, 1:629-640.

30. Dang CV: c-Myc target genes involved in cell growth, apoptosis, and metabolism. Mol Cell Biol 1999, 19:1-11.

31. Scorilas A, Trangas T, Yotis J, Pateras C, Talieri M: Determination of c-myc amplification and overexpression in breast cancer patients: evaluation of its prognostic value against c-erbB-2, cathepsin-D and clinicopathological characteristics using univariate and multivariate analysis. Br J Cancer 1999, 81:1385-1391.

32. Naidu R, Wahab NA, Yadav M, Kutty MK: Protein expression and molecular analysis of c-myc gene in primary breast carcinomas using immunohistochemistry and differential polymerase chain reaction. Int $J$ Mol Med 2002, 9:189-196.

33. Chrzan P, Skokowski J, Karmolinski A, Pawelczyk T: Amplification of c-myc gene and overexpression of c-Myc protein in breast cancer and adjacent non-neoplastic tissue. Clin Biochem 2001, 34:557-562.
34. Amundadottir LT, Johnson MD, Merlino G, Smith GH, Dickson RB: Synergistic interaction of transforming growth factor alpha and c-myc in mouse mammary and salivary gland tumorigenesis. Cell Growth Differ 1995, 6:737-748.

35. Rose-Hellekant TA, Sandgren EP: Transforming growth factor alpha- and c-myc-induced mammary carcinogenesis in transgenic mice. Oncogene 2000, 19:1092-1096.

36. Laban C, Bustin SA, Jenkins PJ: The GH-IGF-I axis and breast cancer. Trends Endocrinol Metab 2003, 14:28-34.

37. Mawson A, Lai A, Carroll JS, Sergio CM, Mitchell CJ, Sarcevic B: Estrogen and insulin/IGF-1 cooperatively stimulate cell cycle progression in MCF-7 breast cancer cells through differential regulation of c-Myc and cyclin D1. Mol Cell Endocrinol 2005, 229:161-173.

38. Conover CA, Hartmann LC, Bradley S, Stalboerger P, Klee GG, Kalli KR, Jenkins RB: Biological characterization of human epithelial ovarian carcinoma cells in primary culture: the insulin-like growth factor system. Exp Cell Res 1998, 238:439-449.

39. Sierra A, Castellsague X, Escobedo A, Moreno A, Drudis T, Fabra A: Synergistic cooperation between C-Myc and BCl-2 in lymph node progression of T1 human breast carcinomas. Breast Cancer Res Treat 1999, 54:39-45.

40. Planas-Silva MD, Bruggeman RD, Grenko RT, Smith JS: Overexpression of cMyc and BCl-2 during progression and distant metastasis of hormonetreated breast cancer. Exp Mol Pathol 2007, 82:85-90.

41. Chen Y, Olopade Ol: MYC in breast tumor progression. Expert Rev Anticancer Ther 2008, 8:1689-1698.

42. Blancato J, Singh B, Liu A, Liao DJ, Dickson RB: Correlation of amplification and overexpression of the c-myc oncogene in high-grade breast cancer: $\mathrm{FISH}$, in situ hybridisation and immunohistochemical analyses. $\mathrm{Br} J$ Cancer 2004, 90:1612-1619.

43. Zhang J, Lu A, Beech D, Jiang B, Lu Y: Suppression of breast cancer metastasis through the inhibition of VEGF-mediated tumor angiogenesis. Cancer Ther 2007, 5:273-286

44. Johansson N, Ahonen M, Kahari VM: Matrix metalloproteinases in tumor invasion. Cell Mol Life Sci 2000, 57:5-15.

45. Deryugina El, Quigley JP: Matrix metalloproteinases and tumor metastasis. Cancer Metastasis Rev 2006, 25:9-34.

46. Sekhon HS, London CA, Sekhon M, Iversen PL, Devi GR: c-MYC antisense phosphosphorodiamidate morpholino oligomer inhibits lung metastasis in a murine tumor model. Lung Cancer 2008, 60:347-354.

47. Magid R, Murphy TJ, Galis ZS: Expression of matrix metalloproteinase-9 in endothelial cells is differentially regulated by shear stress. Role of c-Myc $J$ Biol Chem 2003, 278:32994-32999.

48. Baudino TA, MCKay C, Pendeville-Samain H, Nilsson JA, Maclean KH, White EL, Davis AC, Ihle JN, Cleveland JL: c-Myc is essential for vasculogenesis and angiogenesis during development and tumor progression. Genes Dev 2002, 16:2530-2543.

49. Calvo A, Catena R, Noble MS, Carbott D, Gil-Bazo I, Gonzalez-Moreno O, Huh Jl, Sharp R, Qiu TH, Anver MR, Merlino G, Dickson RB, Johnson MD, Green JE: Identification of VEGF-regulated genes associated with increased lung metastatic potential: functional involvement of tenascinC in tumor growth and lung metastasis. Oncogene 2008, 27:5373-5384.

50. Song Y, Wu J, Oyesanya RA, Lee Z, Mukherjee A, Fang X: Sp-1 and c-Myc mediate lysophosphatidic acid-induced expression of vascular endothelial growth factor in ovarian cancer cells via a hypoxia-inducible factor-1-independent mechanism. Clin Cancer Res 2009, 15:492-501.

51. Frittitta L, Cerrato A, Sacco MG, Weidner N, Goldfine ID, Vigneri R: The insulin receptor content is increased in breast cancers initiated by three different oncogenes in transgenic mice. Breast Cancer Res Treat 1997, 45:141-147.

52. Zhang $X$, Yee D: Tyrosine kinase signalling in breast cancer: insulin-like growth factors and their receptors in breast cancer. Breast Cancer Res 2000, 2:170-175.

53. LeRoith D, Werner $H$, Beitner-Johnson D, Roberts $C T$ Jr: Molecular and cellular aspects of the insulin-like growth factor I receptor. Endocr Rev 1995, 16:143-163.

54. Baxter RC, Bryson JM, Turtle JR: Somatogenic receptors of rat liver: regulation by insulin. Endocrinology 1980, 107:1176-1181. 
55. Calle EE, Kaaks R: Overweight, obesity and cancer: epidemiological evidence and proposed mechanisms. Nat Rev Cancer 2004, 4:579-591.

56. Rotwein P: Structure, evolution, expression and regulation of insulin-like growth factors I, and II. Growth Factors 1991, 5:3-18.

doi:10.1186/bcr3089

Cite this article as: Ferguson et al: Hyperinsulinemia enhances c-Mycmediated mammary tumor development and advances metastatic progression to the lung in a mouse model of type 2 diabetes. Breast Cancer Research 2012 14:R8.

Submit your next manuscript to BioMed Central and take full advantage of:

- Convenient online submission

- Thorough peer review

- No space constraints or color figure charges

- Immediate publication on acceptance

- Inclusion in PubMed, CAS, Scopus and Google Scholar

- Research which is freely available for redistribution

Submit your manuscript at www.biomedcentral.com/submit
C Biomed Central 